\title{
The Efficacy of Low Postoperative Radiation Dose in Patients with Advanced Hypopharyngeal Cancer without High-Risk Factors
}

This article was published in the following Dove Press journal: Cancer Management and Research

\author{
Hengmin Tao ${ }^{1,2}$ \\ Zhong Shen ${ }^{1,2}$ \\ Zhichao Liu ${ }^{1,2}$ \\ Yumei Wei ${ }^{1,2}$
}

'Department of Head and Neck Radiotherapy, Shandong Provincial ENT Hospital, Cheeloo College of Medicine, Shandong University, Jinan, People's Republic of China; ${ }^{2}$ Key Laboratory of Otorhinolaryngology, National Health Commission (Shandong University), Jinan, People's Republic of China
Correspondence: Yumei Wei Email15553I19268@I63.com
Objective: To evaluate the feasibility and efficacy of low postoperative radiotherapy (PORT) dose in patients with advanced hypopharyngeal squamous cell carcinoma (HPSCC) and identify prognostic factors in this group.

Patients and Methods: Between January 2013 and September 2015, 110 consecutive patients with HPSCC with no high-risk factors were treated postoperatively to $50 \mathrm{~Gy}$ $(n=89), 56$ Gy $(n=12)$, and 60 Gy $(n=9)$ in 2 Gy/fraction. Overall survival (OS), 3-year progression-free survival (PFS), 3-year loco-regional recurrence-free survival (LRFS), and treatment-related toxicities were analyzed.

Results: Median follow-up time was 40 months (range $=6-75$ months). The 3 -year localregional control (LRC) and 3-year neck control rate were $86.3 \%$ and $91.8 \%$, respectively. The 3-year OS, PFS, and LRFS were $69.9 \%, 65.5 \%$, and $80.5 \%$, respectively. In a univariate analysis, $\mathrm{T}$ stage showed a significant correlation with improved OS, PFS, and LRFS ( $P=0.008, P=0.039, P=0.034$ ). On multivariate analysis, $\mathrm{T}$ stage showed a significant correlation with improved OS and PFS. N stage showed a significant correlation with improved PFS. However, interval surgery-radiotherapy, reconstructive methods, and RT dose cannot serve as a significant prognostic factor for survival outcome.

Conclusion: This study suggests that treating no high-risk factors for locally advanced HPSCC with a dose of 50 Gy to the whole operative bed and elective lymph node levels cannot compromise disease control and survival.

Keywords: head and neck cancer, hypopharyngeal squamous cell carcinoma, postoperative radiotherapy, quality of care

\section{Introduction}

About 14,400 cases of pharyngeal SCC are diagnosed annually, of which approximately 3400 new cases are HPSCC. ${ }^{1}$ It is well known that head and neck squamous cell carcinoma (HNSCC) requires a comprehensive treatment for the sake of improving the treatment results and survival. Prior to the 1980s, a number of studies have shown a correlation between pathologic features and the risk of recurrence, including surgical status, number, and location of positive neck nodes, presence of extranodal extension (ENE), and perineural invasion. ${ }^{2,4}$ In the meantime, studies from Memorial SloanKettering Cancer Center ${ }^{5,6}$ and M. D. Anderson Hospital ${ }^{7,8}$ demonstrated that adjuvant radiotherapy greatly reduced the risk of local-regional recurrence after surgery alone. Subsequently, postoperative radiotherapy (PORT) became a standard of care for patients with locally advanced HNSCC who experienced surgical resection. 
The dose concept for the treatment of HNSCC by PORT has evolved with time. In the 1970s, one of the first convincing reports on the benefit of combining radiotherapy with surgery was recorded by Fletcher, ${ }^{9}$ and he considered that 50 Gy in 25 fractions was adequate to control microscopic disease. In the 1990s, a dose guideline gained by Peters et $\mathrm{al}^{10}$ in a prospective clinical trial was that 57.6 Gy with daily fractions of 1.8 Gy to surgical bed was needed. Between 1995 and 2000, the EORTC and RTOG cooperative group recommended a dose range from 60-66 Gy according to high-risk status. ${ }^{11,12}$ At present, the recommended dose of PORT for no high-risk factors HPSCC in 2019 NCCN guidelines is 44-50 Gy in $3 \mathrm{D}$ conformal RT or 54-63 Gy with IMRT technique, ${ }^{13}$ in which recommendation for radiation dose in the tumor bed and drainage area are not detailed. Multiple literatures have confirmed the importance of PORT, but the dose of PORT with no high-risk factors is not clear. From January 2013, we give the intensity-modulated radiotherapy (IMRT) dose of 50 Gy to HPSCC patients with no high-risk factors. The aim of the present study was to evaluate the clinical outcomes after this dose change.

\section{Patients and Methods}

A total of 110 consecutive patients, who received PORT of the HPSCC between January 2013 and September 2015 in Shandong Provincial ENT Hospital affiliated to Shandong University, were analyzed. This study was carried out in accordance with the Declaration of Helsinki. Approval for this study was obtained from the ethical committee of Shandong Provincial ENT Hospital. Written informed consent was obtained from all participants. All patients were evaluated preoperatively, including complete history and physical examination, head and neck laryngoscopy, and computed tomography (CT). The tumor stage was determined according to the 2010 American Joint Committee on Cancer (AJCC) TNM staging system (seventh edition). Their clinical characteristics are summarized in Table 1.

\section{Surgery}

All patients received electronic laryngoscopy before operation. Narrow band imaging (NBI) was used to evaluate the canceration range of hypopharyngeal mucosa, and enhanced CT to evaluate the extent of deep tumor invasion. All of the patients in the study underwent surgical resection and unilateral or bilateral neck dissection, typically in nodal levels II-IV, but also in nodal levels I and V, if clinically indicated. The surgical approach was to
Table I Characteristics of II0 Patients

\begin{tabular}{|c|c|}
\hline Characteristics & Number of Cases (\%) \\
\hline Age (years) & $56(39-8 I)$ \\
\hline \multicolumn{2}{|l|}{ Gender } \\
\hline Male & 105 \\
\hline Female & 5 \\
\hline \multicolumn{2}{|l|}{ ECGO performance status } \\
\hline 0 & 39 \\
\hline 1 & 56 \\
\hline 2 & 15 \\
\hline \multicolumn{2}{|l|}{ T-stage (AJCC 7) } \\
\hline 1 & 5 \\
\hline 2 & 28 \\
\hline 3 & 53 \\
\hline 4 & 24 \\
\hline \multicolumn{2}{|l|}{$\mathrm{N}$-stage (AJCC 7) } \\
\hline 0 & 21 \\
\hline 1 & 18 \\
\hline 2 & 69 \\
\hline 3 & 2 \\
\hline \multicolumn{2}{|l|}{ Radiation dose } \\
\hline $50 \mathrm{~Gy}$ & 89 \\
\hline 50-60 Gy & 21 \\
\hline \multicolumn{2}{|l|}{ Interval surgery-radiotherapy } \\
\hline$\leq 4$ weeks & 49 \\
\hline 4-6 weeks & 12 \\
\hline$\geq 6$ weeks & 49 \\
\hline
\end{tabular}

Abbreviations: ECOG, Eastern Cooperative Oncology Group; AJCC, American Joint Committee on Cancer; T, tumor; N, node.

achieve an oncologically complete resection of the primary tumor and the neck dissection was carried out according to clinical stage. The surgical defects were suitably covered by a pectoralis major myocutaneous for the sake of cosmesis and physiological function.

Among all cases, 11 patients (10\%) had the preservation of laryngeal functions after surgery and 99 patients $(90 \%)$ with total pharyngectomy and total laryngectomy. All the patients received bilateral cervical lymph node dissection. Ninety-three cases were treated with different reconstructive methods, 32 patients were reconstructed with a pectoralis major myocutaneous flap. Fifty-eight patients were reconstructed with free jejunum. Three patients had total pharyngo-larygo-oesophagectomy and gastric pull-up.

\section{Pathology}

The pathological report included the following: grade of differentiation, surgical margin, number of nodes with 
extranodal extension (ENE), soft tissue infiltration, and the number and location of positive nodes, pathologic T stage; and pathologic $\mathrm{N}$ stage. High-risk factors included extranodal extension (ENE) and positive margins. T3 or T4 tumors, stage N1, N2, or N3 nodes, perineural invasion, and vascular cancer embolus were regarded as low-risk features with an indication for postoperative RT.

\section{Radiotherapy}

All patients were treated using CT-based RT planning with intensity-modulated radiotherapy (IMRT). Radiotherapy was delivered with a $6 \mathrm{MV}$ linear accelerator. Patients were immobilized from head to shoulders with thermoplastic masks in the supine position. The time interval between surgery and the start of radiotherapy was $<4$ weeks in 49 patients $(44.5 \%), 4-6$ weeks in 12 patients $(10 \%)$, and $>6$ weeks in 49 patients $(44.5 \%)$. All patients have no adverse features, such as extranodal extension (ENE), close or positive surgical margins based on preclinical imaging, operative findings, and final pathologic findings.

Patients underwent the technique of whole-field IMRT. CTV included the surgical bed and elective lymph node chain of both necks. Elective nodal target volume included nodal areas of neck dissection (level II-V nodes and retropharyngeal nodes). The selective nodal target volume of the $\mathrm{pN} 0$ neck consisted of levels II-IV on both necks. CTV was expanded by $0.5 \mathrm{~cm}$ to create planning target volume (PTV). The total dose to the surgical bed was 50 Gy in 25 fractions of 2 Gy. The total dose delivered to selective nodal areas was 50-60 Gy, including 50 Gy (n=89), 56 Gy (n=12), and 60 Gy (n=9).

\section{Follow-Up}

After PORT, patients were followed up every 2 months during the first year, every 3 months in the second year, and every 4-6 months thereafter. During each follow-up period, patients underwent general physical and clinical examinations of the head and neck, including fibrolaryngoscopy, and CT scans to assess the tumor bed, the neck, and to check for any metastases.

\section{Statistical Analysis}

The overall survival (OS) was calculated from the day of start of the adjuvant therapy until death from any cause. Progression-free survival (PFS) was calculated from the day of start of the adjuvant therapy until death from any cause or any relevant events including local, regional, distant recurrence and metastasis, or second tumor. Locoregional recurrence-free survival (LRFS) was observed from the first day of treatment until local and regional recurrence. The statistical tests were performed using SPSS version 17.0. The Kaplan-Meier method was used to estimate OS, PFS, and LRFS. Multivariate analyses were computed using the Cox regression modeling.

\section{Results}

\section{Late Toxicity}

Table 2 shows toxicities in accordance to the Radiation Therapy Oncology Group (RTOG) common toxicity criteria. The rate of grades 3 mucositis was $10 \%(11 / 110)$, the main of acute mucositis was grade $2(62.7 \%)$. Grade 1 and 2 dermatitis were recorded in the majority of patients $(107 /$ $110,97.3 \%$ ). No treatment related deaths were reported and no Grade 4 toxicities occurred among patients, which may be the dose of 50 Gy easily tolerated in our study.

\section{Recurrence and Survival Outcome}

The median study follow-up time was 40 months (range= 6-75 months). Of 110 patients, 15 (13.6\%) patients were observed to have developed the primary site and the neck failure, the actuarial 3-year local-regional control rate according to dose is shown in Table 3 . Conclusions from these data are that: patients receiving 50 Gy had a lower primary and neck failure rate than those receiving $>50 \mathrm{~Gy}$, but those differences did not reach statistical significance $(P=0.082$, $P=0.369$, respectively). The most pattern failure was distant metastasis (17 patients, $15.5 \%$ ), the most common site was the lung. Six patients $(5.4 \%)$ developed secondary cancer.

The OS, PFS, and LRFS are shown in figure 1-figure 3 , respectively. The 3-year OS, PFS, and LRFS rates were $69.9 \%, 65.5 \%$, and $80.5 \%$ respectively.

\section{Prognostic Factors}

We performed univariate and multivariate analysis using variables in this study, including age, sex, $\mathrm{T}$ classification, $\mathrm{N}$ classification, reconstructive methods, interval surgery-

Table 2 Adverse Event Grade According to RTOG Grade

\begin{tabular}{|l|l|l|l|l|}
\hline Toxicity & Grade I & Grade 2 & Grade 3 & Grade 4 \\
\hline Dermatitis & 61 & 46 & 3 & 0 \\
Mucositis & 30 & 69 & $1 \mathrm{I}$ & 0 \\
Dysphagia & 63 & $4 \mathrm{I}$ & 6 & 0 \\
Nausea/Vomiting & 76 & 30 & 4 & 0 \\
Hematologic & 85 & 25 & 0 & 0 \\
toxicity & & & & \\
\hline
\end{tabular}

Abbreviation: RTOG, Radiation Therapy Oncology Group. 
Table 3 3-Years Control Rates at the Primary Site and Neck

\begin{tabular}{|l|l|l|l|l|}
\hline \multicolumn{2}{|l|}{ Primary Site } & \multicolumn{2}{l|}{ Neck } \\
\hline $\begin{array}{l}\text { Dose } \\
\text { (Gy) }\end{array}$ & Recurrence & $\begin{array}{l}\text { Control } \\
\text { Rate (\%) }\end{array}$ & Recurrence & $\begin{array}{l}\text { Control } \\
\text { Rate (\%) }\end{array}$ \\
\hline 50 & 3 & 96 & 6 & 93 \\
$50-60$ & 3 & 85 & 3 & 85 \\
\hline
\end{tabular}

radiotherapy, and $\mathrm{RT}$ dose. By univariate analysis, $\mathrm{T}$ stage ( $P=0.008, P=0.039, P=0.034)$ was associated with improved OS, PFS, and LRFS, while $\mathrm{N}$ stage showed it was associated with PFS $(P=0.029)$. N stage also showed a trend towards improved LRFS $(P=0.052)$. On multivariate analysis, T stage was associated with OS and PFS $(P=0.007, P=0.046)$, and $\mathrm{N}$ stage was associated with PFS and LRFS $(P=0.035$, $P=0.043)$. However, interval surgery-radiotherapy, reconstructive methods, and RT dose did not show as a significant prognostic factor for OS, PFS, and LRFS (Tables 4 and 5).

\section{Discussion}

Over the past two decades, information with regard to dose in the postoperative for no high-risk factors is relatively scarce. After observing excellent outcomes of patients with HPSCC at our institution, ${ }^{14}$ we reduced the intensity- modulated radiotherapy (IMRT) dose from 60 to 50 Gy for all postoperative patients with no high-risk. In the present study, the 3-year local-regional control (LRC), and 3-year neck control rates were $86 \%$ and $91.8 \%$, respectively. In the Peters et al $^{10}$ preliminary study, patients were divided into low risk or high-risk groups after primary surgery, and the low risk patients were irradiated to a total dose of 52.2-54.0 Gy with a fraction size of 1.8 Gy. Based on the first interim analysis, the dose was increased to 57.6 Gy on account of the high rate of recurrences. Biologically equivalent dose calculations show that 52.2 Gy/1.8 Gy per fraction is relatively similar to $51.3 \mathrm{~Gy} / 2$ Gy per fraction, $54 \mathrm{~Gy} / 1.8 \mathrm{~Gy}$ is similar to $53 \mathrm{~Gy} / 2 \mathrm{~Gy}$, and $57.6 \mathrm{~Gy} / 1.8 \mathrm{~Gy}$ is similar to $56.6 \mathrm{~Gy} / 2 \mathrm{~Gy}$. Although Peters et al ${ }^{10}$ used higher doses of 54 and 57.6 Gy compared with the 50 Gy used in our study, the LRC was not improved. Recently, the long-term and final result in the Rosenthal et al $^{15}$ trial showed that increasing the dose did not evidently improve LRC. It is generally believed that doses of 50 Gy are adequate to control microscopic disease. Similarly, Vergeer et al $^{16}$ reported a retrospective study describing the results of selective irradiation up to $50 \mathrm{~Gy}$ in the N0 neck of HPSCC, the 3-year neck control rate was $90 \%$. However, it should be pointed out that only 55 patients

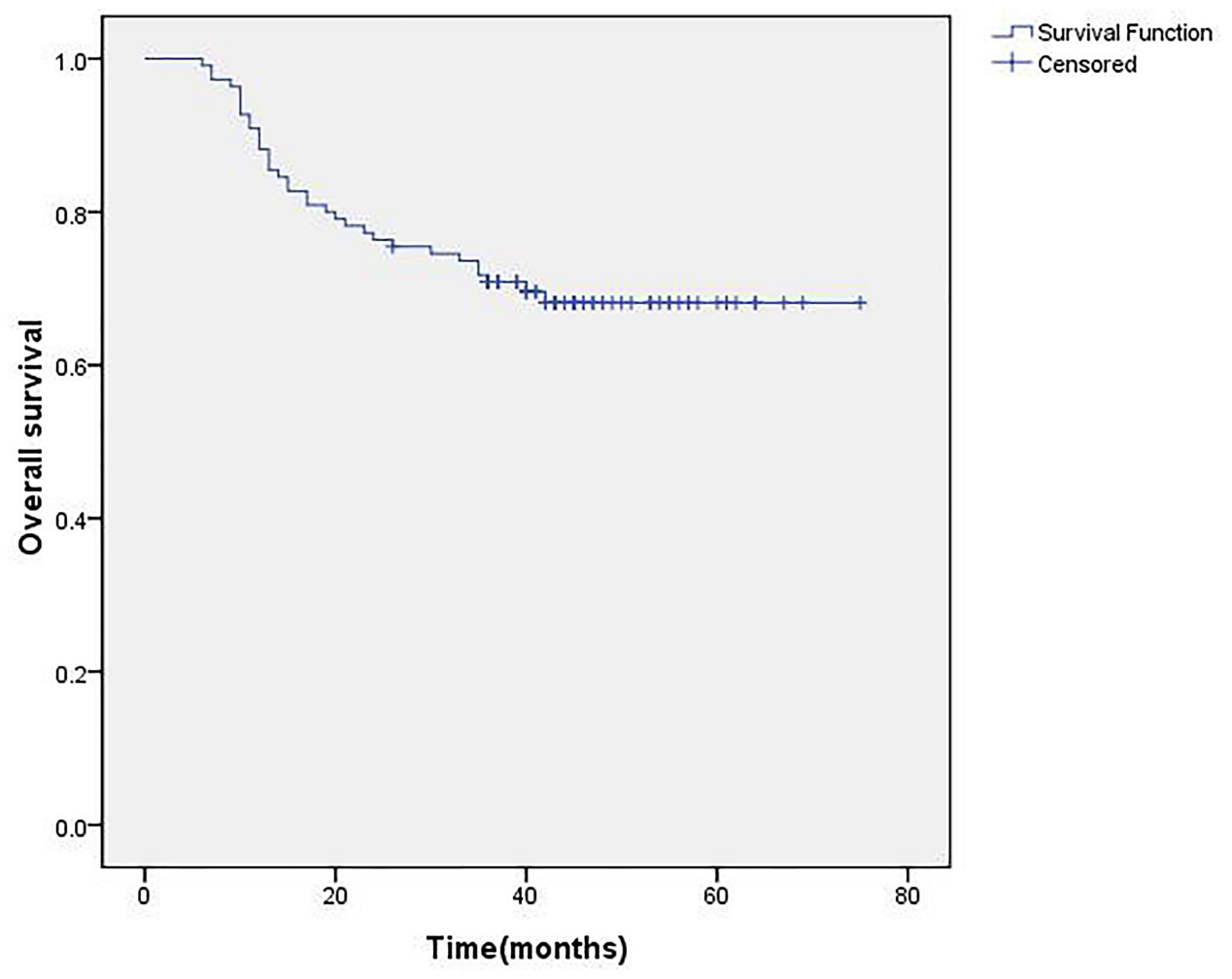

Figure I Overall survival (OS). 


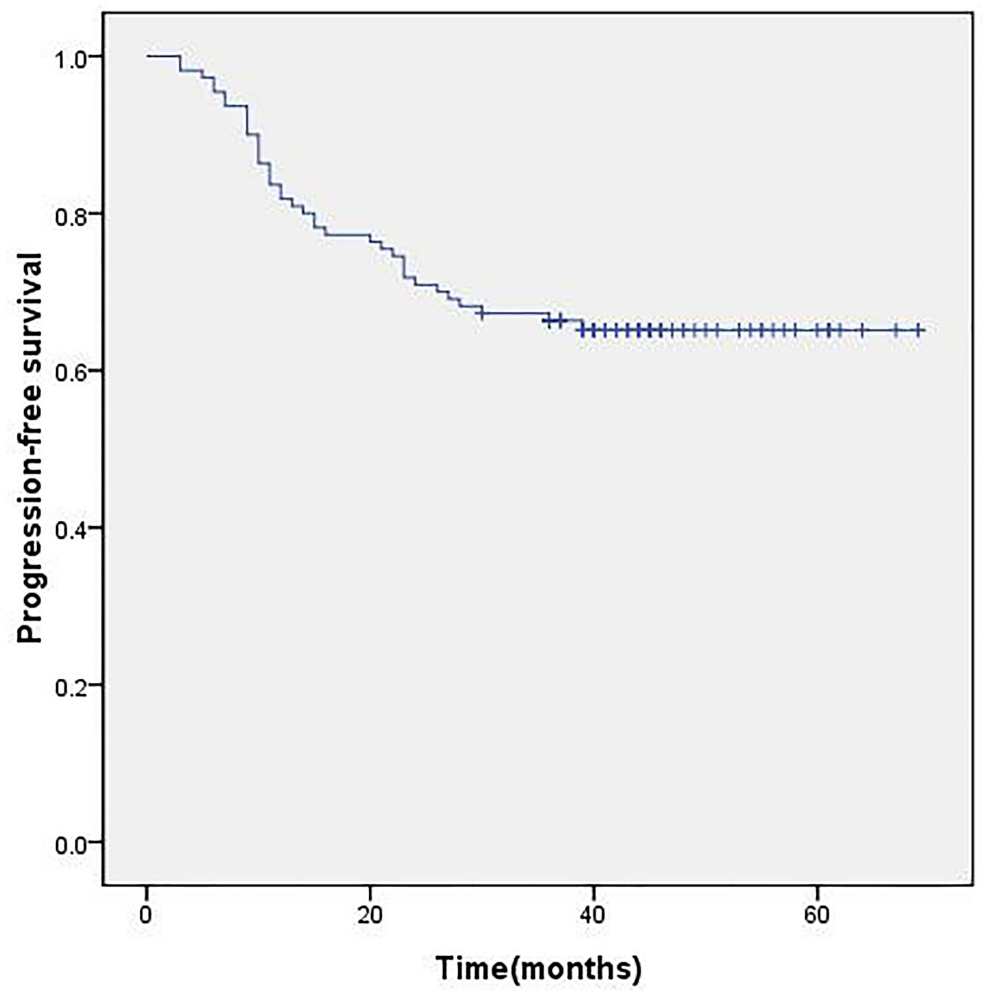

$\neg$ Survival Function

+ Censored

Figure 2 Progression-free survival (PFS)

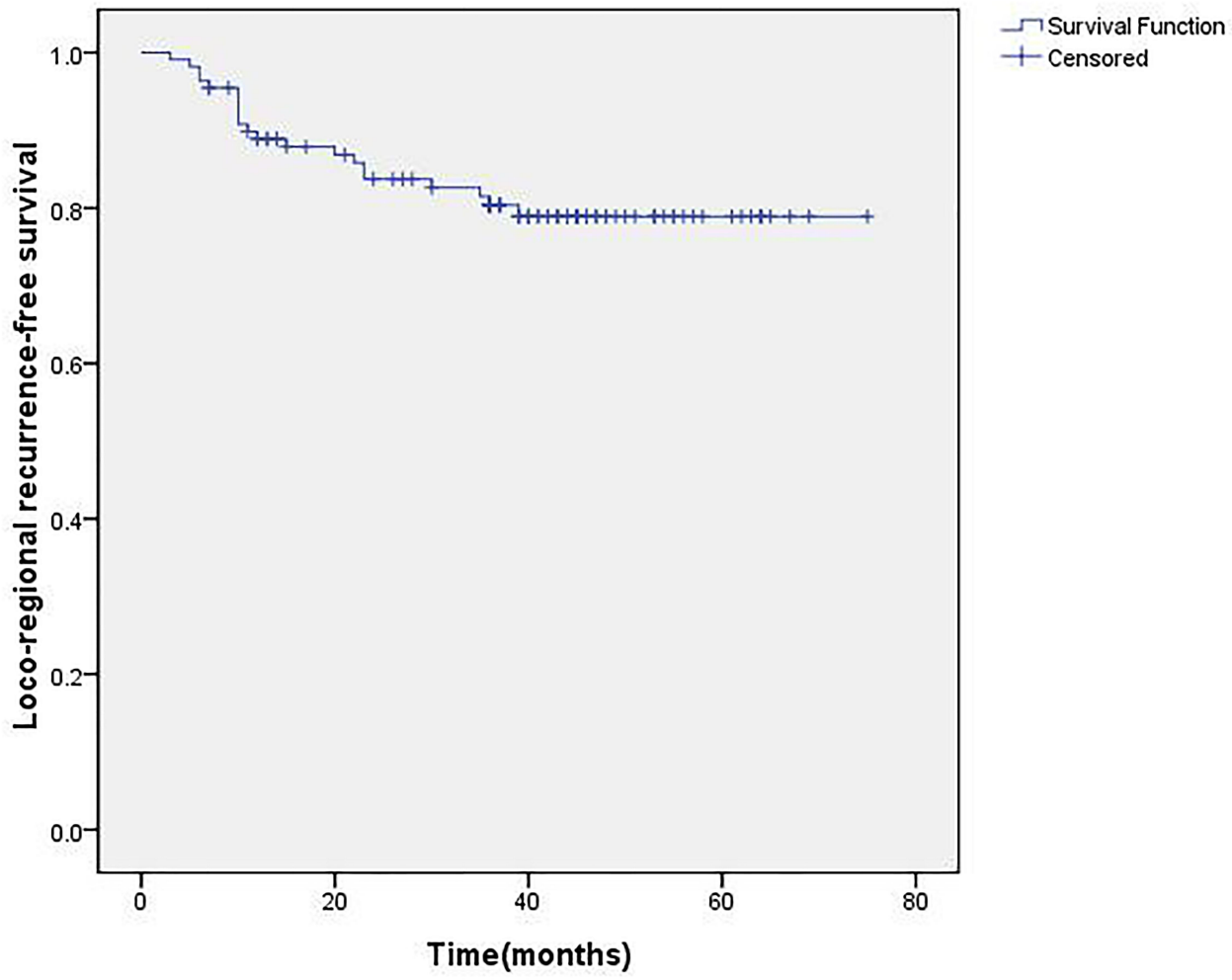

Figure 3 Loco-regional free survival (LRFS). 
Table 4 Univariate Analysis of OS, PFS, and LRFS

\begin{tabular}{|l|l|l|l|l|l|l|}
\hline Factor & OS HR (95\% CI) & P-value & PFS HR (95\% CI) & P-value & LRFS HR (95\% CI) & P-value \\
\hline Age & $1.000(0.96-1.04 I)$ & 0.984 & $0.992(0.955-1.03 I)$ & 0.682 & $1.024(0.972-1.078)$ & 0.373 \\
T classification & $1.934(1.19 I-3.139)$ & 0.008 & $1.588(0.96-1.04 I)$ & 0.039 & $1.95 I(1.050-3.623)$ & 0.034 \\
N classification & $1.500(0.903-2.49 I)$ & 0.118 & $1.792(1.063-3.023)$ & 0.029 & $2.160(0.993-4.698)$ & 0.052 \\
Radiotherapy dose & $1.088(0.474-2.50 I)$ & 0.842 & $1.009(0.489-2.326)$ & 0.872 & $1.584(0.614-4.086)$ & $0.34 I$ \\
Interval surgery-radiotherapy & $1.002(0.976-1.030)$ & 0.857 & $1.000(0.985-1.034)$ & 0.454 & $0.99 I(0.954-1.030)$ & 0.655 \\
Reconstructive methods & $1.086(0.77 I-1.53 I)$ & 0.636 & $0.995(0.7 I 4-1.388)$ & 0.977 & $0.992(0.837-1.947)$ & 0.257 \\
\hline
\end{tabular}

Table 5 Multivariate Analysis of OS, PFS, and LRFS

\begin{tabular}{|c|c|c|c|c|c|c|}
\hline Factor & OS HR $(95 \% \mathrm{Cl})$ & $P$-value & PFS HR $(95 \% \mathrm{CI})$ & $P$-value & LRFS HR (95\% Cl) & $P$-value \\
\hline Age & 1.021 (0.968-I.078) & $0.44 I$ & 1.021 (0.960-I.067) & 1.012 & $1.030(0.974-1.090)$ & 0.301 \\
\hline $\mathrm{T}$ classification & $2.489(1.282-4.833)$ & 0.007 & $1.801(1.009-3.214)$ & 0.046 & $1.84 I(0.965-3.51 \mathrm{I})$ & 0.064 \\
\hline $\mathrm{N}$ classification & $\mathrm{I} .484(0.80 \mathrm{I}-2.749)$ & 0.209 & $1.994(1.050-3.787)$ & 0.035 & $2.129(1.024-4.428)$ & 0.043 \\
\hline Radiotherapy dose & I.195 (0.406-3.520) & 0.747 & $1.243(0.446-3.47 I)$ & 0.677 & $1.533(0.578-4.069)$ & 0.391 \\
\hline Interval surgery-radiotherapy & $\mathrm{I} .404(0.57 \mathrm{I}-3.45 \mathrm{I})$ & 0.459 & $2.313(0.940-5.695)$ & 0.068 & $1.008(0.965-1.053)$ & 0.706 \\
\hline Reconstructive methods & $0.811(0.4 I I-1.600)$ & 0.546 & $0.805(0.422-1.536)$ & 0.511 & $1.339(0.675-2.657)$ & 0.403 \\
\hline
\end{tabular}

were HPSCC. Similar results were reported by Langendijk et al ${ }^{17}$ and Smeele et al. ${ }^{18}$ By contrast, one finding of Lee et $\mathrm{al}^{19}$ was that 3 -year LRC in patients receiving $>60$ Gy was better than in those receiving $<60$ Gy in PORT group (48\% vs $20 \%$ ). A possible explanation for this discrepancy could be the difference of patient selection. It is noteworthing that one finding was better LRC for 50 Gy compared with $>50$ Gy in our study, which suggested that increasing dose was not necessary to improve tumor control. The possible explanation is that increasing the total time may offset any benefit of an increase in the dose.

Additionally, the rate of 3-yeas OS and PFS was $69.9 \%$ and $65.5 \%$ in the current study. The survival outcomes being demonstrated in several studies were similar to our data. In the early 1990s, Frank et $\mathrm{al}^{20}$ reported a retrospective analysis of 110 HPSCC treated with $4 \mathrm{meV}$ photons, irradiating the primary site and bilateral neck using 1.8-2.0 Gy per fraction up to a total dose of median 60 Gy. The 5-year OS was $48 \%$. The study by Kirke et $\mathrm{al}^{21}$ retrospectively analyzed 3518 head and neck squamous cell carcinoma patients (111 hypopharyngeal cancer) and found that the rate of 3-year OS for PORT was $67.5 \%$. Huang et $\mathrm{al}^{22}$ conducted a comparison between surgery alone and PORT, finding that 3-year DFS was $45 \%$ in the PORT group. In one analysis of 74 patients with HPSCC, 44 patients received PORT with a dose of 60-66 Gy and 30 patients received concurrent chemoradiation, 3-year OS for PORT was
$44 \% .{ }^{19}$ Although Lee et al ${ }^{19}$ delivered a higher dose of 60-66 Gy compared with the 50 Gy in our research, the 3 -year OS was lower than our result. One reason could be that the delivered doses were likely less precise.

In this analysis, although we used a dose of $50 \mathrm{~Gy}$ to the whole operatived bed instead of a boost of $60 \mathrm{~Gy}$, there was no reduction in locoregional control rate. This may be related to the following three likely reasons: 1) All patients analyzed in our study were HPSCC, the homogeneity of the cases improved the results of the study. 2) More refined techniques of intensity-modulated RT were used to deliver the PORT, and dose refinement with such advanced techniques had benefited a large number of patients. 3) Total hypopharyngeal resection or circumferential resection of hypopharyngeal could ensure the safe surgical margins and improved the local control rate.

In our study, no patients experienced grade 4 dermatitis, dysphagia, hematologic toxicity, or nausea/vomiting. The rate of grades 3 and 4 mucositis $(10.6 \%, 10 / 94)$ was comparable with the $11.4 \%$ reported by Mohanti et $\mathrm{al}^{23}$ and the $19 \%$ reported by Lee et $\mathrm{al}^{24}{ }^{24}$ which did not raise the need for hospital care and nasogastric tube. The study by Machtay et $\mathrm{al}^{25}$ demonstrated patients receiving $\leq 50 \mathrm{~Gy}$ had a lower rate of severe toxicity than patients receiving $>60 \mathrm{~Gy}$. As evidenced in the Peters et $\mathrm{al}^{10}$ and Chin et $\mathrm{al}^{26}$ trials, there was a dose-response for complications.

The present study revealed that $\mathrm{T}$ staging was significantly associated with OS, PFS, and LRFS while N staging showed a significant correlation with improved PFS and LRFS. These 
discoveries accorded with the available data in the literature. $\mathrm{T}$ staging and $\mathrm{N}$ staging have been previously considered to be independent prognostic factors for LRC and for OS in patients with locally advanced HNSCC. ${ }^{27,28}$ However, interval surgery-radiotherapy was not a significantly prognostic factor in this analysis. Prior published studies have shown the effects of different time-to-PORT intervals on locoregional recurrence and survival were beneficial in some cases, ${ }^{29-32}$ and ineffective in others. ${ }^{33-35}$ Possible explanations were a retrospective and small sample size. Most importantly, both multivariate and univariate analysis revealed that RT dose was not predictive of treatment outcomes, and the difference dose did not influence survival outcome. This finding further supports the view that patients with no high-risk factors treated to 50 Gy was sufficient.

In conclusion, we presently suggest that treating no high-risk factors for locally advanced HPSCC with a dose of 50 Gy in 25 fractions of 2 Gy each to the surgical bed and elective lymph node levels cannot compromise disease control and survival. A larger series of patients and longer-term follow-up result remain necessary.

\section{Disclosure}

The authors report no conflicts of interest in this work.

\section{References}

1. Edge SB, Compton CC. The American Joint Committee on Cancer: the 7th edition of the AJCC Cancer staging manual and the future of TNM. Ann Surg Oncol. 2010;17(6):1471-1474. doi:10.1245/s10434010-0985-4

2. Carter RL, Tanner HS, Clifford P, Shaw HJ. Peri-neural spread in squamous cell carcinoma of the head and neck: a clinico-pathologic study. Clin Otolaryngol. 1979;4:271-281. doi:10.1111/j.13652273.1979.tb01900.x

3. Johnson JT, Barnes EL, Myers EN, Schramm VL, Borochovitz D, Sigler BA. The extracapsular spread of tumors in cervical node metastasis. Arch Otolaryngol. 1981;107:725-729. doi:10.1001/ archotol.1981.00790480001001

4. Shah JT, Cendon RA, Farr HW, Strong EW. Carcinoma of the oral cavity: factors affecting treatment failure at the primary site and neck. Am J Surg. 1976;32:504-507. doi:10.1016/0002-9610(76)90328-7

5. Barkley HT, Fletcher GH, Jesse RH, Lindberg RD. Management of cervical lymph node metastases in squamous cell carcinomas of the tonsillar fossa, base of tongue, supraglottic larynx and hypopharynx. Am J Surg. 1972;124:462-467. doi:10.1016/0002-9610(72)90067-0

6. Feldman M, Fletcher GH. Analysis of the parameters relating to failures above the clavicles in patients treated by postoperative irradiation for squamous cell carcinoma of the oral cavity or oropharynx. Int J Radiat Oncol Biol Phys. 1982;8(1):27-30. doi:10.1016/03603016(82)90380-7

7. Vikram B, Strong EW, Shah JP, Spiro R. Failure at the primary site following multimodality treatment in advanced head and neck cancer. Head Neck Surg. 1984;6:720-723. doi:10.1002/hed.2890060303

8. Vikram B, Strong EW, Shah JP, Spiro R. Failure in the neck following multimodality treatment for advanced head and neck cancer. Head Neck Surg. 1984;6:724-729. doi:10.1002/hed.2890060304
9. Fletcher GH. Clinical dose response curve of subclinical aggregates of epithelial cells and its practical application in the management of human cancers. In: Friedman M, editor. Biological and Clinical Basis of Radiosensitivity. Springfield, IL: Charles C. Thomas, Pub.; 1974:485-501.

10. Peters LJ, Goepfert H, Ang KK, et al. Evaluation of the dose for postoperative radiation therapy of head and neck cancer: first report of a prospective randomized trial. Int J Radiat Oncol Biol Phys. 1993;26(1):3-11. doi:10.1016/0360-3016(93)90167-T

11. Cooper JS, Pajak TF, Forastiere AA, et al. Postoperative concur rent radiotherapy and chemotherapy for high-risk squamous-cell carcinoma of the head and neck. N Engl J Med. 2004;350(19):1937-1944.

12. Bernier J, Domenge C, Ozsahin M, et al. Postoperative irradiation with or without concomitant chemotherapy for locally advanced head and neck cancer. $N$ Engl $J$ Med. 2004;350(19):1945-1952. doi:10.1056/NEJMoa032641

13. National Comprehensive Cancer Network. NCCN Clinical Practice Guidelines in Oncology (NCCN Guidelines): Head and Neck Can-Cers. Fort Washington, PA: National Comprehensive Cancer Net-work; 2019.

14. $\mathrm{Xu} \mathrm{W,} \mathrm{Lv} \mathrm{ZH,} \mathrm{Sa} \mathrm{N,} \mathrm{et} \mathrm{al.} \mathrm{Treatment} \mathrm{and} \mathrm{prognosis} \mathrm{of} 264$ patients with hypopharyngeal carcinoma.Zhonghua. Er Bi Yan Hou Tou Jing Wai Ke Za Zhi. 2018;53(5):346-351.

15. Rosenthal DI, Mohamed AS, Garden AS, et al. Final report of a prospective randomized trial to evaluate the dose-response relationship for postoperative radiation therapy and pathologic risk groups in patients with head and neck cancer. Int J Radiat Oncol Biol Phys. 2017;98(5):1002-1011. doi:10.1016/j.ijrobp.2017.02.218

16. Vergeer MR, Doornaert PA, de Bree R, Leemans CR, Slotman BJ, Langendijk JA. Postoperative elective nodal irradiation for squamous cell carcinoma of the head and neck: outcome and prognostic factors for regional recurrence. Ann Oncol. 2011;22:2489-2494. doi:10.1093/ annonc/mdq768

17. Langendijk JA, Slotman BJ, van der Waal I, Doornaert P, Berkof J, Leemans CR. Risk-group definition by recursive partitioning analysis of patients with squamous cell head and neck carcinoma treated with surgery and postoperative radiotherapy. Cancer. 2005;104:14 08-1417. doi:10.1002/cncr.21340

18. Smeele LE, Leemans CR, Langendijk JA, et al. Positive surgical margins in neck dissection specimens in patients with head and neck squamous cell carcinoma and the effect of radiotherapy. Head Neck. 2000;22:559-563. doi:10.1002/1097-0347(200009)22:6<559:: AID-HED3>3.0.CO;2-7

19. Lee MS, Ho HC, Hsiao SH, Hung SK. Treatment results and prognostic factors in locally advanced hypopharyngeal cancer. Acta Otolaryngol. 2008;128(1):103-109. doi:10.1080/00016480701387116

20. Frank JL, Garb JL, Kay S, et al. Postoperative radiotherapy improves survival in squamous cell carcinoma of the hypopharynx. Am J Surg. 1994;168:476-480. doi:10.1016/S0002-9610(05)80105-9

21. Kirke DN, Qureshi MM, Kamran SC, et al. Role of adjuvant chemoradiotherapy in T4N0 stage IV head and neck cancer: a National Cancer Database ana-lysis. Head Neck. 2018;40 (6):1174-1184. doi:10.1002/hed.25087

22. Huang DT, Johnson CR, Schmidt-Ullrich R, Grimes M. Postoperative radiotherapy in head and neck carcinoma with extracapsular lymph node extension and/or positive resection margins: a comparative study. Int $J$ Radiat Oncol Biol Phys. 1992;23(4):737-742. doi:10.1016/0360-3016(92)90646-Y

23. Mohanti BK, Thakar A, Kaur J, et al. Postoperative radiotherapy dose requirement in standard combined-modality practice for head and neck squamous cell carcinoma: analysis of salient surgical and radiotherapy parameters in 2 cohorts. Head Neck. 2017;39(9):1788-1796. doi: $10.1002 /$ hed. 24836

24. Lee JH, Song JH, Lee SN, et al. Adjuvant postoperative radiotherapy with or without chemotherapy for locally advanced squamous cell carcinoma of the head and neck: the importance of patient selection for the postoperative chemoradiotherapy. Cancer Res Treat. 2013;45 (1):31-39. doi:10.4143/crt.2013.45.1.31 
25. Machtay M, Moughan J, Farach A, et al. Hypopharyngeal dose is associated with severe late toxicity in locally advanced head-andneck cancer: an RT-OG analysis. Int $J$ Radiat Oncol Biol Phys. 2012;84(4):983-989. doi:10.1016/j.ijrobp.2012.03.005

26. Chin RI, Spencer CR, DeWees T, et al. Reevaluation of postoperative radiation dose in the management of human papillomavirus-positive oropharyngeal cancer. Head Neck. 2016;38(11):1643-1649.

27. Budach V, Stuschke M, Budach W, et al. Hyperfractionated accelerated chemoradiation with concurrent fluorouracil mitomycin is more effective than dose-escalated hyperfractionated accelerated radiation therapy alone in locally advanced head and neck cancer: final results of the radiotherapy cooperative clinical trials group of the German Cancer Society 95-06 Prospective Randomized Trial. J Clin Oncol. 2005;23:1125-1135. doi:10.1200/JCO.2005.07.010

28. Jeremic B, Milicic B. Pretreatment prognostic factors of local recurrence-free survival in locally advanced squamous cell carcinoma of the head and neck treated with radiation therapy with or without concurrent chemotherapy. Am J Clin Oncol. 2008;31:213-218. doi:10.1097/COC.0b013e318161dbef

29. Vikram B. Importance of the time interval between surgery and postoperative radiation therapy in the combined management of head \& neck cancer. Int J Radiat Oncol Biol Phys. 1979;5:1837-1840. doi:10.1016/0360-3016(79)90568-6

30. Parsons JT, Mendenhall WM, Stringer SP, Cassisi NJ, Million RR. An analysis of factors influencing the outcome of postoperative irra- diation for squamous cell carcinoma of the oral cavity. Int $J$ Radiat Oncol Biol Phys. 1997;39:137-148. doi:10.1016/S0360-3016(97)00152-1
31. Huang J, Barbera L, Brouwers M, Browman G, Mackillop WJ. Does delay in starting treatment affect the outcomes of radiotherapy? A systematic review. J Clin Oncol. 2003;21:555-563. doi:10.1200/ JCO.2003.04.171

32. Shaikh T, Handorf EA, Murphy CT, Mehra R, Ridge JA, Galloway TJ. The impact of radiation treatment time on survival in patients with head and neck cancer. Int J Radiat Oncol Biol Phys. 2016;96:967-975. doi:10.1016/j.ijrobp.2016.08.046

33. Graboyes EM, Gross J, Kallogjeri D, et al. Association of compli- ance with process-related quality metrics and improved survival in oral cavity squamous cell carcinoma. JAMA Otolaryngol Head Neck Surg. 2016;142:430-437. doi:10.1001/ jamaoto.2015.3595

34. Bastit L, Blot E, Debourdeau P, Menard J, Bastit P, Le Fur R. Influence of the delay of adjuvant postoperative radiation therapy on relapse and survival in oropharyngeal and hypopharyngeal cancers. Int $J$ Radiat Oncol Biol Phys. 2001;49:139-146. doi:10.1016/S0360-3016(00)01376-6

35. Marshak G, Rakowsky E, Schachter J, et al. Is the delay in starting postoperative radiotherapy a key factor in the outcome of advanced (T3 and T4) laryngeal cancer? Otolaryngol Head Neck Surg. 2004;131:489-493. doi:10.1016/j.otohns.2004.02.042

\section{Publish your work in this journal}

Cancer Management and Research is an international, peer-reviewed open access journal focusing on cancer research and the optimal use of preventative and integrated treatment interventions to achieve improved outcomes, enhanced survival and quality of life for the cancer patient.
The manuscript management system is completely online and includes a very quick and fair peer-review system, which is all easy to use. Visit http://www.dovepress.com/testimonials.php to read real quotes from published authors. 